Article (refereed) - postprint

Tavassoli, Hamid Reza; Tahershamsi, Ahmad; Acreman, Mike. 2014.

Classification of natural flow regimes in Iran to support environmental flow management [in special issue: Hydrological science for environmental flows] Hydrological Sciences Journal, 59 (3-4). 517-529. $\underline{10.1080 / 02626667.2014 .890285}$

Copyright (C) 2014 IAHS Press

This version available http://nora.nerc.ac.uk/508569/

NERC has developed NORA to enable users to access research outputs wholly or partially funded by NERC. Copyright and other rights for material on this site are retained by the rights owners. Users should read the terms and conditions of use of this material at http://nora.nerc.ac.uk/policies.html\#access

This is a pre-copy-editing, author-produced PDF of an article accepted for publication in Hydrological Sciences Journal following peer review. The definitive publisher-authenticated version 59 (3-4). 517-529. is available online at 10.1080/02626667.2014.890285:

Contact CEH NORA team at noraceh@ceh.ac.uk

The NERC and CEH trademarks and logos ('the Trademarks') are registered trademarks of NERC in the UK and other countries, and may not be used without the prior written consent of the Trademark owner. 


\title{
Classification of natural flow regimes in Iran to support environmental flow management
}

\author{
Hamid R. Tavassoli*, Ahmad Tahershamsi*, Mike Acreman** \\ * Civil \& Environmental Engineering Dep., Amirkabir Univ. of Technology, Tehran, Iran \\ ** Center for Ecology \& Hydrology, Wallingford, United Kingdom \\ htavassoli@aut.ac.ir
}

\begin{abstract}
Development of environmental flow standards at the regional scale has been proposed as a means to manage the influence of hydrological alterations on riverine ecosystems, in view of the rapid pace of global water resources development. Flow regime classification forms a critical part in such environmental flow assessments. We hereby present a national-scale classification of hydrological regimes for Iran based on a set of hydrological metrics. It describes ecologically-relevant characteristics of the natural hydrological regime derived from 15-47 year records of daily mean discharge data for 539 stream gauges within a 47-year period. The classification was undertaken using a fuzzy partitional method within Bayesian mixture modelling. The analysis resulted in 12 classes of distinctive flow-regime types differing in various hydrologic aspects. This classification is being used for further research on regional scale environmental flow studies in Iran.
\end{abstract}

Key words environmental flow; hydrologic classification; indicators of hydrologic alteration, Iranian rivers, natural flow regime

The natural flow regime of rivers is known as the dominant factor in shaping riverine ecosystem structures and processes (Power et al., 1995). The increasing need for water and the corresponding human activities in the rivers and their catchments alter the pattern of variations in river flows and cause ecological alterations (Poff et al., 1997). Knowledge of these temporal and spatial hydrological patterns and their ecological consequences is therefore essential for sustainable water allocation in river systems (Arthington \& Pusey, 2003). Rivers with similar natural hydrological features should have similar ecological functions (Poff \& Ward, 1989) and analogous ecological responses to the same changes in their flow regime (Arthington et al., 2006; Poff et al., 2010). Based on this assumption, ecological responses to hydrological alterations in one river can be predicted from the knowledge of the response in a similar river. This has been a key assumption in a scientific consensus for assessing environmental flow standards at the regional scale, entitled the ecological limits of hydrologic alterations (ELOHA) framework (Poff et al, 2010). As part of this framework, using a set of ecologically-relevant flow variables, river segments within the region are classified into a few distinctive flow regime types that are expected to have different ecological characteristics. This natural flow regime classification can be used for synthesising studies of flow alteration-ecological response relationships and the transfer of the results of such studies to rivers of the same type. Therefore, classification of natural flow regimes underpins the development of environmental flow research and management at a regional scale, especially when there are insufficient time and financial resources available for river-by-river environmental flow studies (Poff et al, 2010). Thresholds of departures from the natural flow regime that maintain good ecological status in different river types have been used to set abstraction licences in the UK to achieve the objectives of the European Water Frameowrok Directive (Acreman and Ferguson, 2010).

Hydrological classifications have been performed around the world with a variety of purposes. In particular, there have been several recent studies on differentiating river segments based on ecologically meaningful hydrological parameters for supporting environmental flow 
management in a range of countries including Australia (Kennard et al, 2010; Moliere et al., 2009), New Zealand (Snelder et al., 2005), North America and Northern Europe (Kingston et al., 2011), Spain (Alba \& Leroy, 2012; Belmar et al., 2011), France (Snelder et al., 2009), USA (Reidy Liermann et al., 2012) and China (Zhang et al., 2012).

In this paper, we present the first ever national-scale classification of hydrological regimes for Iranian rivers based on a set of ecologically-relevant hydrological metrics derived from long-term daily discharge measurements for a large set of stream gauges throughout the country.

\section{METHODS \\ Study area}

Iran has a total area of 1,648,195 $\mathrm{km}^{2}$ and lies between $25^{\circ} 00^{\prime}$ and $39^{\circ} 47^{\prime} \mathrm{N}$ and $44^{\circ} 02^{\prime}$ and $63^{\circ} 20^{\prime} \mathrm{E}$. Thus, the southern half of the country is in the subtropical zone and the northern half of the country in the temperate zone with a desert zone in the middle, at around $30^{\circ} \mathrm{N}$. Iran is generally mountainous with altitudes varying from 56 metres below sea level to $5670 \mathrm{~m}$ above sea level; more than half of the country is at altitudes between 1,000-2,000 $\mathrm{m}$ and $16 \%$ is above 2,000 m with some mountains of 3,000-4,000 $\mathrm{m}$. The mean altitude of the country is approximately 1,250 metres and that of the Central Plateau is $900 \mathrm{~m}$.

Iran has a variable climate, but approximately $85 \%$ of the country is arid, semi-arid or hyper-arid. The peculiar features and location result in the country receiving an average annual precipitation of $246 \mathrm{~mm}$. This is unevenly distributed across the country (less than $200 \mathrm{~mm}$ in $28 \%$ of the country and $100 \mathrm{~mm}$ in $96 \%$ of the county). Only the Caspian Sea coast receives more than 1,000 mm of rain annually. Two major mountain ranges influence the climate: the Zagros chains in the west and the Alborz in the north. Most humid clouds come from the west, but the mountains prevent clouds from reaching central, eastern and southern parts, so the central and southern lowlands and eastern parts of the country receive very little precipitation. Due to low precipitation and unevenly distributed precipitation in these areas, most rivers flow only seasonally and this flows depends directly upon the amount of rainfall.

\section{Discharge Data}

Daily mean discharge data for 1597 gauges were acquired from the Iranian Ministry of Energy. All data from these gauges were screened and a subset fulfilling the following criteria were selected: (i) little or no hydrological modification due to human activities; (ii) a period of hydrologic record of more than 15 years within the period 23 Sep. 1961 to 22 Sep. 2008; and (iii) continuous daily mean discharge data, where possible. Our objective was to maximise the number and spatial coverage of gauges available for inclusion, whilst ensuring the stream gauges were comparable in terms of data quality and quantity. Criterion 1 was assessed by locating dams and major water abstractions upstream of the gauges. Criterion 2 was based on the conclusions of Kennard et al. (2009) that estimation of hydrological metrics should be based on at least 15 years of discharge record. This makes the records suitable for use in hydrological classification analyses that aim to characterize spatial variation in hydrologic regimes, provided that the discharge records were contained within a discrete temporal window (i.e. preferably $>50 \%$ overlap between records). Data from pre-regulation periods meeting these criteria were also selected by removing post-regulation data. 
In total, 539 stream gauges met these screening criteria, which represent our best efforts to identify a subset of least-disturbed stream gauges in Iran. The majority of the selected gauges (70\%, 381 of 539 gauges) had continuous daily flow data with the remainder being most frequently (80\%) characterized by missing less than 30 days of data. Missing periods of record, which were all shorter than 30 days, were in-filled using linear interpolation. The period of record for all gauges was within the water years 1961-62 to 2008-09 and 376 (70\%) of gauges included the middle year (1985). Some 389 (72\%) of gauges had at least 20 years of record and only $40(7 \%)$ had only 15 years of data i.e. the minimum length of record for inclusion in the classification analysis (Fig. 1a). Pair-wise overlapping of the gauges is shown in Figure1b. The geographical location and length of discharge record for each of the 539 gauges is shown in Figure 2. Gauge density was greatest in the north-western catchment of Urmia lake (III) with $10.8 \%$ of all gauges covering 3.3\% of the country's area. The catchments of the Caspian Sea (I) with $30.2 \%$ of the gauges in $10.9 \%$ of the area and Karakum catchment (VI) with $5.4 \%$ of the gauges in $2.7 \%$ of the area also have good densities. The Persian Gulf and Oman Sea catchment (II) with $31.2 \%$ of the gauges in $26 \%$ of the area and the Central catchment (IV) with $22.2 \%$ of the gauges in $50.8 \%$ of the area and the Eastern border catchment (V) with only one $(0.2 \%)$ gauge in $6.3 \%$ of the country's area are the least dense networks. Gauges were situated on streams and rivers with a wide range of upstream catchment areas (5-51454 km²) but most (75\%) have drainage areas of $100-10,000 \mathrm{~km}^{2}$.

\section{Hydrological metrics}

A river's hydrograph presents a complex signal of variations in flow over time. There are many metrics available for describing regime characteristics. The natural flow regime paradigm (Poff et al, 1997) assumes that all components of the hydrograph are exploited by some organism or biological community, making this a very holistic approach. It hypotheses that any change in the flow regime from natural will cause a change in the river ecosystem and that there are limits to flow regime alteration beyond which there is high risk of major ecological change. To make analysis practical it is necessary to identify a subset of components of the hydrological regime of rivers that are most ecologically relevant, with which to measure hydrological change. Olden \& Poff (2003) concluded that the 66 hydrological metrics calculated by the Indicators of Hydrologic Alteration (IHA) software package (Mathews \& Richter, 2007) can adequately describe most of the major flow-regime components that influence the river ecosystem.

All 66 metrics analysed by Olden and Poff were selected for this study to characterise daily flow time series. These metrics were :

(1) monthly flow magnitude - central tendency and dispersion measures of monthly flow magnitudes averaged across the record length (2x12 parameters)

(2) magnitude and duration of annual maximum and minimum flows (2x12 parameters),

(3) timing of annual extreme flows ( $2 \times 2$ parameters),

(4) frequency and duration of high and low pulses which are defined as the mean flow plus or minus standard deviation( $2 \times 4$ parameters $)$ and

(5) rate and frequency of flow changes ( $2 \times 3$ parameters).

The metrics are explained in Table 1. 
Before calculating the metrics, flow magnitudes for each gauge were standardized by diving by mean daily flow calculated over its whole record period in order to make rivers of different flow sizes comparable in the classification. Metrics were calculated using Indicators of Hydrologic Alteration (IHA) Ver. 7.1 (The Nature Conservancy, 2009).

\section{Statistical analysis}

A key element of the study was to define a set of hydrologically-heterogenous groups of rivers, with respect to the metric selected, with each group being as internally hydrologically homogeneous as possible. Hydrological classification was undertaken using a fuzzy partitional method, Bayesian Mixture modelling, implemented using the AutoClass C program (v 3.3.4 Cheeseman \& Stutz, 1996). In Bayesian mixture modelling, the observed distribution of date is modelled as a mixture of a finite number of component distributions to determine the number of distributions, their parameters, and object membership (Webb et al., 2007). The approach is fully probabilistic and uncertainty is explicitly reported in terms of data specification, class specification and the final classification chosen. Multiple plausible classifications are produced, which are then ranked on their estimated marginal likelihoods to select the most parsimonious classification that is guaranteed to have the highest posterior probability; i.e. the probability of the model being correct given the data (Cheesman \& Stutz, 1996; Webb et al., 2007 cited in Kennard et al., 2010). All of the 66 metrics were modelled as normally distributed continuous variables after being $\log _{10}(\mathrm{x}+1)$ transformed. Outputs from the analysis include: the probability of class membership for each object (gauge); class strength (the probability that the attribute distributions at the class level can be used to predict the class members, with strong classes tending to have tight distributions of attribute values); and the importance of the individual attributes for distinguishing each class. This is evaluated using the Kullback-Leibler distance, a measure of distance between data distributions, which accounts for the central tendency and variability of the data distribution. The summed Kullback-Leibler distances over all attributes provided an estimate of overall divergence of each class from the overall distribution of cases (Kennard et al., 2010). Classification was performed several times to select the most likely Bayesian solution according to the calculated marginal likelihoods for each conducted classification.

\section{RESULTS \\ Hydrological Classification}

The most likely classification from the Bayesian clustering analysis produced 12 classes reflecting distinctive flow-regime types. The majority of stream gauges (91.5\%) had a $\geq 99.9 \%$ probability of belonging to only one class (Fig 3a). Only 7 of the 539 gauges exhibited a class membership probability of $<0.990$ for their most likely class. Classes varied in their divergence (i.e hydrological difference) from the global distribution. Class 3 exhibited the greatest classlevel divergence with respect to the global class, while classes 2 and 8 had the least class-level divergence and the remainder nine classes had generally equivalent divergence values (Fig. $3 \mathrm{~b}$ ). Classes 1,3,4,7 and 9 had the greatest class strength relative to the global distribution, indicating comparatively low within-class variation in hydrological characteristics, whereas classes 5 \& 11 had the lowest class strength (Fig 3c).

\section{Hydrological and geographical characteristics of flow-regime classes}


The twelve flow-regime classes could be first broadly grouped into perennial $(1,5,6,7,9,10,11 \& 12)$ and intermittent (2,3,4,11 \& 8). Class 8 rivers rarely cease, classes 2,3 \& 11 regularly stop flowing and class 4 is extremely intermittent (Fig 4a). Further distinctions among classes are evident in terms of seasonal timing of discharge (Fig 4b). Spatial distribution of the classified gauges are shown in Fig. 5 on a terrain map of Iran showing main catchment boudaries as well.

Magnitudes of selected metrics are shown for all the gauges present in each flow-regime class in Figure 6. These graphs display distinctions between the classes and have been used for interpreting the characteristics of the flow-regime in each class in the following paragraphs.

\section{Flow-regime class 1}

The rivers and streams that have been classified as class 1 are perennial, have relatively constant flow and possess a high base flow contribution. There are no zero flow days reported in the discharge records of these rivers. Most of these gauging stations are located in the north eastern part of the country. The streams are spread along the northern boundaryof Alborz mountains and western edges of Zagros mountains.

\section{Flow-regime class 2}

These rivers are characterized by low flows is summer and high flows in winter. Almost all of them have low annual mean flows and a low constancy of mean daily flow (Colwell, 1974) to predictability of mean daily flow (Colwell, 1974) ratio, which indicates their periodical behaviour. Other characteristics of this class are low minimum flows and low base-flow index.

\section{Flow-regime class 3}

These rivers show relatively high flows in summer after a wet spring season. Flows are not high in winter and fall suggesting the dependence of these rivers on snowmelt. The annual coefficient of variance is low in this class and constancy to the predictability ratio is high. Baseflow index is high suggesting dependence of the river on groundwater. Flow rise rates and the number of zero flow days are low. Low annual 1-day maximum flows suggest continuous source of water from the mountains' melting snows. The gauges are mostly located on the edges of high mountains.

\section{Flow-regime class 4}

Rivers in this class exhibit the most intermittent behaviour among all classes and are characterized by very low flows in summer and autumn. The highest flows are observed in spring and the streams are situated in high altitudes. Almost all gauges show low annual mean flow and large number of days with zero flow. The base-flow index is low as well as the number of hydrological reversals. These streams cease to flow when all the snow feeding them has melted.

\section{Flow-regime Class 5}

The flow regimes in these rivers are dominant by winter runoff, almost all gauges show low annual mean flows and are characterised by a high coefficient of variation. Low annual minimum flows, high annual 1-day maximum flows, high flow rise rates and low number of reversals are among the other characteristics of this group of rivers and streams. Most of these 
gauges are located far from high mountains and mostly in the southern parts of the country where flashy floods occur after rainfalls.

\section{Flow-regime Class 6}

The most notable feature of this class is high discharge in the autumn, relatively low flows in spring and relatively high flows in summer. All gauge altitudes are low and all are located in the humid catchments (I) near the Caspian Sea. Minimum flows are observed around June/July and maximum flows are expected in October, which contrasts with all other classes. High numbers of low pulses with short durations and large reversal numbers suggest their dependence on rainfall.

\section{Flow-regime class 7}

Relatively low flows in autumn, high flows in spring and low summer flows describe these rivers. All gauges are located in high altitude areas, they have relatively small upstream catchments and are characterized by low annual mean flows. Base flow indices are low, suggesting the dependence of these streams on snow-melt. Most of the gauges are located in the mountains of the north west.

\section{Flow-regime class 8}

The flow regime in this class is spring dominant with low annual mean flows. Annual minimum flow magnitudes are also low as are base flow indices. All the gauges are located in the northern band of the country.

\section{Flow-regime class 9}

This class is dominated by the large rivers in the south west of the county. The members of this class have a relatively constant flow with higher discharges in winter and spring and relatively low flows in the summer. The annual coefficient of variation is low and flow rise rates are low.

Flow-regime class 10

A relatively constant flow-regime characterizes the members of this class. Relatively high summer flows, small number of zero-flow days and high base flow rates are signs of dependence of these rivers on groundwater resources.

\section{Flow-regime class 11}

High summer flows, followed by wet springs and low flows in the winter, low mean annual flows and high constancy index values, high variability of base flow index among the members and later than normal occurrence of maximum and minimum flow suggest the relation of these streams with groundwater.

\section{Flow-regime Class 12}

These rivers have steady flows with maximum discharge in spring. All the gauges are located in high altitudes and recorded low mean annual flows. Flow constancy is high in this class as well as the number of hydrologic reversals. Most of the gauges are located in the north east of the county. 


\section{DISCUSSION}

Iran is experiencing a fast pace of water resources development. Implementation of best international practice, such as Integrated Water Resources Management, must include assessment of the allocation of water to different sectors, including public supply, irrigation and hydropower and maintenance of sufficient water to conserve biodiversity and ecosystem services (Acreman et al., this volume) that support human livelihoods and well-being (MEA, 2005). Alteration of flow regimes world-wide has led to substantial loss of biodiversity and ecosystem services (Vörösmarty et al., 2010). This is the first study of its kind in Iran and focused on hydrological classification of rivers as a first step to understanding different river ecosystem types in various environments within the country. Ideally, this analysis would be complemented by assessment of river organisms and communities, such as fish, macro-invertebrates, macrophytes and algae. However, there is a significant lack of ecological data for the rivers in Iran, thus initial steps to investigate the setting environmental flow standards was undertaken through analysis of ecologically relevant flow regime characteristics.

Even in this endeavour, we faced two major restrictions, in this study which also apply to similar studies limited to hydrological data and spread on a diverse environment: (1) Rivers entered in this study are those which have relatively long records of daily flow, which are not available for all river types in the country. Caution should be exercised when using short records; analysis of flow records for the UK River Thames (since 1850) show that flows since the early 1960s (when many UK gauge records start) are not representative of longer period variations (Hannaford \& Marsh, 2006). Gauging stations are rare on many intermittent or ephemeral rivers which form a large number of the rivers in Iran. Modelled data may be recruited for covering this restriction. (2) The study covers a region with very diverse environments in terms of climate, geology, topography and evolutionary ecology. A provisional analsyis showed that there was an imperfect relationship between geographical distribution of fish species and flow regime class distributions. This was probably due to variations in other factors influencing river ecosystems, such as temperature, nutrient status and $\mathrm{pH}$, that are independent of the flow regime. We believe we need to employ other environmental parameters for narrowing the flow regime classes into smaller classes with ecological relevance for environmental flow studies.

Some analysis was undertaken to better define the relationship between flow regime and physical characteristics of the drainage basins. For example, it was noted that some classes (e.g. classes 1 and 8 high base flow, class 7 low base flow) are characterised by a high base flow contribution. It was hypothesised that these catchments would be dominated by impermeable geology. However, it was not possible to easily explain the classification based on geological data. In contrast there was a strong relationship between streams with snow-melt and existence of mountains within the catchment (such as class 7).

This paper marks the start of environmental flow analysis in Iran and provides an underpinning hydro-ecological classification on which future ecological and physical environment studies can be based. It provides a substantial step-forward within the country to help improve Integrated Water Resources Management by allowing consideration of ecological and ecosystem services within decisions on water allocation and infrastructure development.

Acknowledgements We thank S. Lotfi \& S. Torabi from the Iranian Ministry of Energy's office of policy making and water allocation for providing the data used in this study. We also 
appreciate helpful comments from C. Laize and J. Hannaford from the Centre for Ecology \& Hydrology (CEH), UK.

\section{References}

Acreman, M.C., Ferguson, A. 2010 Environmental flows and European Water Framework Directive. Freshwater Biology 55, 32-48

Acreman, M.C., Overton, I., King, J., Wood, P., Cowx, I., Dunbar, M.J., Kendy, E., Young, W. (in review) The changing role of science in environmental flows Hydrological Sciences Journal.

Alba Solans, M. and Leroy Poff, N. ,2012. Classification of Natural Flow Regimes in the Ebro Basin (Spain) by using a Wide Range of Hydrologic Parameters. River Research and Applications, River Research and Applications, in press.

Arthington, A.H. \& Pusey, B.J., 2003. Flow restoration and protection in Australian rivers. River Research and Applications, 19, 1-19.

Arthington, A.H., Bunn, S.E., Poff, N.L., and Naiman R.J., 2006. The challenge of providing environmental flow rules to sustain river ecosystems. Ecological Applications, 16, 13111318.

Belmar, O., Velasco, J., and Martinez-Capel, F., 2011. Hydrological classification of natural flow regimes to support environmental flow assessments in intensively regulated Mediterranean rivers, Segura River Basin (Spain). Environmental Management, 47, 9921004.

Cheeseman, P. and Stutz, J., 1996. Bayesian classification (Autoclass): theory and results. In: Advances in Knowledge Discovery and Data Mining (Ed. U. Fayyad), pp. 153-180. AAAI Press and MIT Press, Cambridge, MA, U.S.A.

Colwell, R.K., 1974. Predictability, constancy and contingency of periodic phenomena. Ecology 55: 1148-1153.

Hannaford, J., Marsh, TJ. 2006 Ann assessment of trends in UK runoff and low flows using a network of undisturbed catchments International Journal of Climatology, 26, 1237-1253

Kennard, M.J., Pusey, B.J., Olden, J.D., Mackay, S.J, Stein, J.L, Marsh, N., 2010. Classification of natural flow regimes in Australia to support environmental flow management. Freshwater Biology, 55, 171-193.

Kingston, D.G. , Hannah, D.M., Lawler, D.M., Mcgregor, G.R., 2011. Regional classification, variability, and trends of northern North Atlantic river flow. Hydrological Processes, 25, 1021-1033.

Mathews, R. and Richter, B.D., 2007. Application of the indicators of hydrologic alteration software in environmental flow setting. Journal of the American Water Resources Association, 43, 1400-1413.

Millennium Ecosystem Assessment 2005 Ecosystems and Human Well-being: Wetlands and Water Synthesis. World Resources Institute, Washington.

Olden, J.D., Kennard, M.J., Pusey, B.J., 2011. A framework for hydrologic classification with a review of methodologies and applications in ecohydrology. Ecohydrology 5, 503-518.

Poff, N.L., Allan, J.D., Bain, M.B., Karr, J.R., Prestegaard, K.L., Richter, B.D., Sparks, R.E. and Stromberg, J.C., 1997. The natural flow regime: a paradigm for river conservation and restoration. BioScience, 47, 769-784. 
Poff, N.L. and Ward, J.V., 1989. Implications of streamflow variability and predictability for lotic community structure: a regional analysis of stream flow patterns. Canadian Journal of Fisheries and Aquatic Sciences, 46, 1805-1818.

Poff, N.L., Richter, B.D., Arthington, A.H., Bunn, S.E., Naiman R.J., Kendy, E., Acreman, M., Apse, C., Bledsoe, B.P., Freeman, M.C., Henriksen, J., Jacobson, R.B., Kennen, J.G., Merritt, D.M., O’Keeffe, J.H., Olden, J.D., Rogers, K., Tharme, R.E. and Warner, A., 2010. The ecological limits of hydrologic alteration (ELOHA): a new framework for developing regional environmental flow standards. Freshwater Biology, 55, 147-170.

Power, M.E., Sun, A., Parker, G., Dietrich, W.E. and Wootton, J.T., 1995. Hydraulic food-chain models. BioScience, 45,159-167.

Reidy Liermann, C.A., Olden, J.D., Beechie, T.J., Kennard, M.J., Skidmore, P.B., Konrad, C.P. and Imaki, H., 2012. Hydrogeomorphic classification of Washington State rivers to support emerging environmental flow management strategies. River Research and Applications, 28, 1340-1358.

Snelder, T.H., Biggs, B.J.F. and Woods, R.A., 2005. Improved eco-hydrological classification of rivers. River Research and Applications, 21, 609-628.

Snelder, T.H., Lamouroux, N., Leathwick, J.R., Pella, H., Sauquet, E., Shankar, U., 2009. Predictive mapping of the natural flow regimes of France. Journal of Hydrology, 373, 5767.

The Nature Conservancy, 2009. Indicators of Hydrologic Alteration Version 7.1 User's

Manual.Vörösmarty, C.J., P. B. McIntyre, M. O. Gessner, D. Dudgeon, A. Prusevich, P.

Green, S. Glidden, S. E. Bunn \& C. A. Sullivan, C. Reidy Liermann \& P. M. Davies 2010.

Global threats to human water security and river biodiversity. Nature, 467: 555-561.

Webb, J.A., Bond, N.R., Wealands, S.R., Mac Nally, R., Quinn, G.P., Vesk, P.A. and Grace, M.R., 2007. Bayesian clustering with AutoClass explicitly recognises uncertainties in landscape classification. Ecography, 30, 526-536.

Zhang, Y., Arthington, A.H., Bunn, S.E., Mackay, S., Xia, J., Kennard, M., 2012.

Classification of flow regimes for environmental flow assessment in regulated rivers: The Huai riverbasin, China. River Research and Applications, 28, 989-1005. 